\title{
GAMBARAN PENGENALAN MODEL PEMBELAJARAN QODE (QUESTIONING, ORGANIZING, DOING AND EVALUATING) PADA GURU IPA SMP DI KABUPATEN PROBOLINGGO
}

\author{
THE DESCRIPTION OF INTRODUCTION QODE (QUESTIONING, ORGANIZING, DOING AND \\ EVALUATING) LEARNING MODEL AT SCIENCE TEACHER IN PROBOLINGGO
}

\author{
Retno Irawati ${ }^{1, a}$ \\ ${ }^{1}$ Science teacher in SMP Negeri 1 Dringu, Probolinggo \\ Jl. Yos Sudarno Pabean Dringu, Probolinggo 67271, Indonesia \\ e-mail:aira.retno99@gmail.com
}

\begin{abstract}
Abstrak
Penelitian ini merupakan penelitian yang berisi tentang gambaran sintak model pembelajaran QODE pada guru IPA tingkat SMP di kabupaten Probolinggo. Adapun sintak dari model QODE adalah bagian dari keterampilan yang sudah dimiliki guru IPA. Jenis penelitian ini adalah penelitian deskriptif dilaksanakan pada bulan September 2015 dengan jumlah koresponden 25 guru IPA dari SMP Negeri di Kabupaten Probolinggo. Data diperoleh melalui instrumen penelitian berupa angket berisi tentang pertanyaan tertulis yang merupakan bagian dari sintak model pembelajaran QODE. Hasil penelitiannya adalah keterampilan guru membimbing siswa untuk bertanya 84\%, keterampilan guru membimbing siswa untuk berdiskusi $72 \%$, keterampilan guru membimbing siswa untuk merencanakan kegiatan eksperimen $88 \%$, keterampilan siswa untuk mempresentasikan hasil eksperimen $76 \%$ dan keterampilan guru mengadakan evaluasi terhadap materi 96\%. Kesimpulan penelitian ini bahwa keterampilan yang sudah dikuasai oleh guru dapat dijadikan sebagai gambaran pengenalan sintak model QODE dalam pembelajaran IPA pada materi Fisika, Biologi, dan Kimia di SMP.
\end{abstract}

Keywords: Model Pembelajaran QODE, sintaks, keterampilan guru.

\begin{abstract}
This research is about the description that contains syntax of QODE learning model on science teacher of Junior High in Probolinggo. The syntax of the QODE model is part of skills that already possessed by a science teacher. This research is a descriptive study, conducted in September 2015 by the number of correspondents 25 science teachers from Junior High School in Probolinggo. Data obtained through research instruments in the form of written questionnaire containing questions that were part of QODE learning model syntax. Research results were the skills of teachers to guide students to ask $84 \%$, the skills of teachers to guide students to discuss $72 \%$, the skills of teachers to guide students to plan experiments $88 \%$, students' skills to present the results of experiment $76 \%$ and the skills of teachers to conduct an evaluation of learning material 96\%. The conclusion of this study was that the skills that have been
\end{abstract}

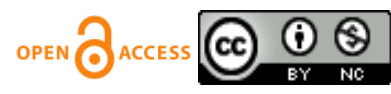


mastered by teacher can give a description and recognition of the syntax of QODE model (syntax) in science learning Physics, Biology, and Chemistry in Junior High School.

Keywords: QODE Learning model, syntax, teacher skills.

Copyright @2015 Jurusan Fisika FMIPA Universitas Negeri Surabaya

\section{PENDAHULUAN}

Sekolah merupakan salah satu wahana pembentuk karakter bangsa dan lokasi yang penting dimana para "Nation Builders" Indonesia diharapkan bisa memperjuangkan guna membawa negara kita untuk bersaing di kancah global. Sejalan dengan tantangan global yaitu tantangan dunia pendidikan akan menjadi semakin besar, hal ini akan mendorong siswa untuk memperoleh prestasi terbaik. Tetapi dalam dunia pendidikan di Indonesia mengalami beberapa kendala yang berhubungan dengan kualitas pendidikan antara lain keterbatasan akses pada pendidikan, banyaknya guru yang tidak merata, serta kompetensi guru itu sendiri dinilai masih kurang.

Sebagai guru pernah terfikir bagaimana siswa kita akan aktif dalam proses belajar mengajar. Sehingga hal ini merupakan bukti bahwa Kegiatan Belajar Mengajar kita berhasil. Peran aktif siswa dalam Proses belajar mengajar dapat ditunjukkan dengan kegiatan tanya jawab. tetapi, mayoritas siswa memiliki rasa tidak percaya diri apabila diminta mengajukan pertanyaan. Contohnya: "Anak-anak ada yang ingin ditanyakan dari materi yang telah ibu ajarkan ?" Pasti siswa menjawab sudah jelas bu atau tidak ada bu. Atau mungkin juga ada siswa yang ingin bertanya tapi tidak berani, takut diejek temannya, takut pertanyaannya salah dll.

Demikian pula menurut [1], guru berperan dalam kegiatan belajar mengajar meliputi : 1. guru sebagai demonstrator, menguasai bahan atau materi yang akan diajarkan dan mengembangkannya, 2. guru sebagai pengelola kelas, memanajemen kelas dengan baik dengan cara menyediakan kesempatan bagi siswa sedikit demi sedikit mengurangi ketergantungan kepada guru, 3. guru sebagai mediator dan fasilitator, memiliki pengetahuan dan pemahaman yang cukup untuk media pendidikan, karena media pendidikan merupakan alat komunikasi yang lebih efektif dalam pembelajaran, sebagai fasilitator, mampu mengusahakan sumber belajar yang dapat menunjang pencapaian tujuan, 4. guru sebagai evaluator, tujuannya untuk mengetahui apakah tujuan yang telah dirumuskan tercapai atau belum, materi yang diajarkan sudah dikuasai siswa.

Untuk lebih merangsang keaktifan siswa dalam bertanya, maka kami menyusun Model QODE (Questioning, Organizing, Doing and Evauating). Model Pembelajaran QODE (Questioning, Organizing, Doing and Evaluating) adalah model pembelajaran yang dibagi ke dalam 4 tahap, yaitu 1).Questioning, 2). Organizing, 3). Doing and 4). Evaluating lebih jelasnya diuraikan sebagai berikut :

Tahap 1). Questioning, adalah tahapan dimana peserta didik memiliki keterampilan bertanya, setelah melihat tayangan slide peristiwa yang berhubungan dengan IPA dalam kehidupan sehari-hari. Sesuai dengan Kurikulum 2013 peserta didik diharapkan dapat mengamati dan menanya pada tahap ini terhadap fakta, konsep, prosedur atau hal lain yang abstrak dengan bimbingan guru [2]. 
Tahap 2). Organizing adalah tahapan guru membimbing peserta didik dengan mengorganisasikan 4 siswa kedalam kelompok belajar. Pada tahap ini peserta didik diharapkan mampu mendiskusikan dalam satu kelompok tentang pertanyaan yang diperoleh agar menemukan jawabannya. Dan juga guru sebagai fasilitator dalam diskusi kelas dalam membahas pertanyaan yang dimiliki tiap kelompok untuk menemukan jawabannya [3].

Tahap 3). Doing adalah tahap melaksanakan praktikum secara berkelompok untuk menemukan kebenaran konsep yang sudah didiskusikan. Pada tahap ini dibutuhkan kerjasama dan diskusi peserta didik dalam satu kelompok agar menghasilkan data pengamatan yang mendekati sempurna dan membutuhkan bimbingan guru.

Tahap 4). Evaluating, pada tahap ini peserta didik diharapkan dapat mempresentasikan hasil praktikum secara berkelompok dan dapat menjelaskan proses serta kejadian yang dialami selama praktikum. Dalam hal ini guru berperan membimbing peserta didik untuk memperoleh konsep yang benar.

Dalam penelitian ini diharapkan keterampilan yang dimiliki guru mata pelajaran IPA di Kabupaten Probolinggo dapat digunakan sebagai gambaran pengenalan sintak Model Pembelajaran QODE (Questioning, Organizing, Doing and Evauating).

\section{METODE PENELITIAN}

Penelitian ini merupakan penelitian deskriptif, yaitu penelitian yang dilaksanakan untuk mendapatkan gambaran atau deskripsi tentang keadaan secara deskritif [4]. Instrumen penelitian berupa angket yang menjelaskan tentang sejumlah pertanyaan tertulis untuk dijawab secara tertulis oleh responden [5]. Penelitian ini dilakukan pada bulan September 2015, dengan responden 25 guru IPA dari 16 SMP Negeri di Probolinggo. Kemudian data yang diperoleh dianalisis menggunakan deskriptif kuantitatif dalam bentuk persentase dengan bantuan Microsoft Excel for Windows.

\section{HASIL PENELITIAN DAN DISKUSI}

Berikut ini disajikan data hasil angket yang disebar sebagai pelaksanaan pembelajaran tentang keterampilan yang dimiliki oleh guru IPA SMP di Kabupaten Probolinggo.

Tabel 1. Keterampilan yang dimiliki guru

\begin{tabular}{|c|c|c|c|c|}
\hline No & Variabel & Jawaban & Jumlah & $\%$ \\
\hline \multirow[t]{2}{*}{1} & membimbing & $\mathrm{Ya}$ & 21 & 84 \\
\hline & $\begin{array}{l}\text { siswa untuk } \\
\text { bertanya }\end{array}$ & Tidak & 4 & 16 \\
\hline \multirow[t]{6}{*}{2} & membimbing & $\mathrm{Ya}$ & 18 & 72 \\
\hline & $\begin{array}{ll}\text { siswa } & \text { untuk } \\
\text { berdiskusi } & \end{array}$ & Tidak & 7 & 28 \\
\hline & $\begin{array}{l}\text { mengenai suatu } \\
\text { pertanyaan }\end{array}$ & & & \\
\hline & mengenai materi & & & \\
\hline & pelajaran yang & & & \\
\hline & diajarkan & & & \\
\hline \multirow[t]{4}{*}{3} & membimbing & $\mathrm{Ya}$ & 22 & 88 \\
\hline & siswa & Tidak & 3 & 12 \\
\hline & melaksanakan & & & \\
\hline & kegiatan praktikum & & & \\
\hline \multirow[t]{3}{*}{4} & membimbing & $\mathrm{Ya}$ & 19 & 76 \\
\hline & $\begin{array}{l}\text { siswa untuk } \\
\text { mempresentasikan }\end{array}$ & Tidak & 6 & 24 \\
\hline & hasil praktikum & & & \\
\hline \multirow[t]{4}{*}{5} & mengadakan & $\mathrm{Ya}$ & 24 & 96 \\
\hline & evaluasi terhadap & Tidak & 1 & 4 \\
\hline & materi yang & & & \\
\hline & diajarkan & & & \\
\hline
\end{tabular}

Berdasarkan Tabel 1, diketahui bahwa keterampilan guru saat mengadakan evaluasi terhadap materi yang diajarkan $96 \%$ dan yang tidak $14 \%$. Gambaran tentang 
keterampilan yang dimiliki oleh guru IPA dapat ditunjukkan oleh grafik berikut:

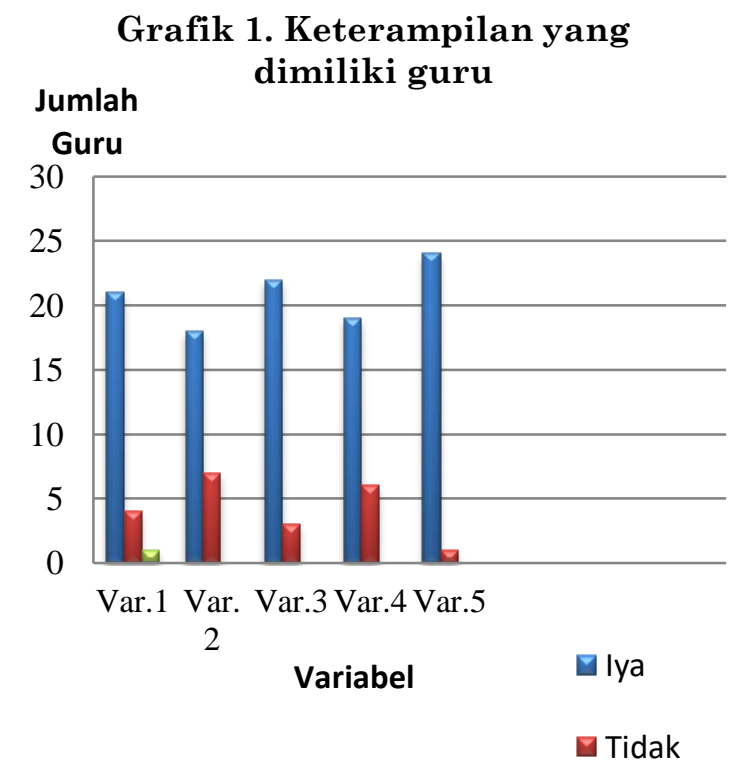

\section{Keterangan:}

Variabel 1 : Guru membimbing siswa untuk bertanya

Variabel 2 : Guru membimbing siswa untuk berdiskusi mengenai suatu pertanyaan mengenai materi pelajaran yang diajarkan

Variabel 3 : Guru membimbing siswa untuk melaksanakan kegiatan praktikum

Variabel 4 : Guru membimbing siswa untuk mempresentasikan hasil praktikum

Variabel 5 : Guru mengadakan evaluasi terhadap materi yang diajarkan

Penguasaan keterampilan guru IPA yang ditunjukkan oleh grafik antara lain keterampilan menanya sudah dilakukan oleh 21 orang dari 25 orang, dengan alasan untuk mengecek apakah siswa sudah menyerap materi pada hari itu, mengarahkan, membimbing dan memotivasi supaya siswa paham tentang materi yang diajarkan dan menumbuhkan rasa ingin tahu, siswa tidak bisa membuat pertanyaan dengan kalimat yang disusun sendiri, melatih keberanian siswa untuk bertanya.

Guru membimbing siswa untuk berdiskusi mengenai suatu pertanyaan mengenai materi pelajaran yang diajarkan sebanyak 22 orang dari 25 orang guru dengan alasan, Agar jawaban - jawaban siswa sesuai dengan materi yang sedang dibahas, melatih komunikasi, hubungan siswa dan mengemukakan pendapat, jujur, toleransi, terbiasa berargumen dalam berdiskusi.

Guru membimbing siswa untuk melaksanakan kegiatan praktikum sebanyak 22 orang dari 25 orang guru IPA dengan alasan, karena dengan praktikum siswa cenderung lebih ingat pada suatu konsep, dapat membuktikan kebenaran konsep, agar tujuan dan tehnik sama, siswa terkadang tidak mengerti tentang LKS yang dimiliki, kemampuan siswa yang berbeda, melatih keterampilan sains, menerapkan metode ilmiah.

Guru membimbing siswa untuk mempresentasikan hasil praktikum sebanyak 19 orang dari 25 orang guru dengan alasan, agar semua anggota kelompok mengetahui hasil dari praktikum yang didasari sikap jujur, apa adanya dan rasa ingin tahu, menumbuhkan keberanian dan percaya diri, menemukan kesimpulan, mengkomunikasikan hasil praktikum.

Dari 25 orang guru, sebanyak 24 orang mengadakan evaluasi terhadap materi yang diajarkan, dengan alasan untuk mengetahui daya serap siswa terhadap materi yang dipelajari, agar guru tahu seberapa besar siswa tersebut paham terhadap praktikum yang dilakukan, untuk mengetahui tingkat pemahaman siswa terhadap materi yang telah 
diajarkan, mengetahui ketercapaian siswa pada KD tersebut.

Keterampilan yang dimiliki oleh guru IPA di kabupaten Probolinggo dapat dijadikan dasar pengenalan sintak Model Pembelajaran QODE.

\section{KESIMPULAN}

Berdasarkan hasil penelitian, keterampilan yang dimiliki guru dalam pembelajaran IPA SMP di Probolinggo sudah berkualitas tinggi, oleh karena itu sebagai guru IPA kita senantiasa diharapkan untuk menguasai berbagai strategi pembelajaran dalam meningkatkan dan mengoptimalkan kemampuan berfikir siswa, sehingga diperoleh suatu pembelajaran yang aktif, efektif dan efisien. Selain itu, keterampilan yang dimiliki oleh guru dapat dijadikan seagai gambaran pengenalan sintak Model Pembelajaran QODE (Questioning, Organizing, doing and Evaluating) dalam pembelajaran IPA di SMP.

\section{UCAPAN TERIMA KASIH}

Ucapan terima kasih ini kami sampaikan kepada:

1. Bapak Agus Ismara Wibowo, S.Pd selaku
Kepala SMP Negeri 1 Dringu, yang telah memberikan ijin sehingga terselasaikan penulisan makalah ini.

2. Bapak/ Ibu Guru koresponden, yang telah bersedia meluangkan waktu mengisi angket yang kami sebarkan.

3. Agus Wachid, MM suami tercinta yang selalu memberikan motivasi sampai terselesaikan makalah ini

\section{DAFTAR PUSTAKA}

[1] Rusman. Model-Model pembelajaran Mengembangkan Profesional Guru. Jakarta: PT Rajagrafindo Persada; 2011.

[2] Zubaidah S, Mahanal S, dan Yulianti L. Ragam Model Pembelajaran IPA SMP. Malang: Universitas Negeri Malang; 2013.

[3] Aqib Z. Model - Model, Media dan Strategi Pembelajaran Kontekstual (Inovatif). Bandung: Yrama Widya; 2013.

[4] Sugiyono. Metode Penelitian Pendidikan Pendekatan Kuantitatif, Kualitatif, dan $R \& D$. Bandung: Alfabeta; 2015.

[5] Nawawi H. Metodologi Penelitian Bidang Sosial. Yogyakarta: Gajah Mada University Prees; 2011. 